\title{
Effect of two universal adhesives on microshear bond strength of resin cement to zirconia
}

\section{Wpływ dwóch uniwersalnych systemów łączących na wytrzymałość na mikrościnanie wiązania cementu kompozytowego do cyrkonu}

\author{
Shila Emamieh ${ }^{A, D, F}$, Mahya Elahi ${ }^{A, B}$, Amir Ghasemi ${ }^{E, F}$ \\ Shahid Beheshti University of Medical Sciences, Tehran, Iran \\ A - research concept and design; $B$ - collection and/or assembly of data; $C$ - data analysis and interpretation; \\ $D$ - writing the article; $E$ - critical revision of the article; $F$ - final approval of the article
}

Address for correspondence

Shila Emamieh

E-mail: shilaemamieh@gmail.com

\section{Funding sources}

None declared

Conflict of interest

None declared

Received on December 28, 2018

Reviewed on March 18, 2019

Accepted on May 14, 2019

Published online on July 23, 2019

Cite as

Emamieh S, Elahi M, Ghasemi A. Effect of two universal adhesives on microshear bond strength of resin cement to zirconia. Dent Med Probl. 2019;56(3):245-249. doi:10.17219/dmp/109349

DOI

$10.17219 / \mathrm{dmp} / 109349$

Copyright

๑ 2019 by Wroclaw Medical University

This is an article distributed under the terms of the

Creative Commons Attribution 3.0 Unported License (CC BY 3.0)

(https://creativecommons.org/licenses/by/3.0/)

\begin{abstract}
Background. Considering the increasing demand of patients for esthetic and durable restorations, zirconia, with its excellent mechanical properties, has overcome most of the limitations of all-ceramic restorations. However, bonding to zirconia is still challenging.

Objectives. This study compared the effect of 2 universal adhesives on the microshear bond strength of resin cement to zirconia after $24 \mathrm{~h}$ and 6 months of water storage.

Material and methods. This in vitro experimental study was performed on 56 zirconia (Prettau ${ }^{\circledR}$ Zirconia) blocks, which were randomly divided into 2 groups. The Scotchbond ${ }^{\text {TM }}$ Universal single-component adhesive and the All-Bond Universal ${ }^{\mathrm{TM}}$ 2-component adhesive were used. The PANAVIA ${ }^{\mathrm{TM}} \mathrm{F} 2.0$ resin cement was bonded to all samples, and they were stored in distilled water for $24 \mathrm{~h}$ and 6 months. The microshear bond strength test was then performed, and the data was analyzed using the Kruskal-Wallis and Mann-Whitney tests.

Results. After $24 \mathrm{~h}$ of water storage, the All-Bond samples showed significantly higher microshear bond strength than the Scotchbond samples $(p<0.001)$, but at 6 months, the microshear bond strength of Scotchbond was higher. The bond strength of All-Bond decreased after 6 months $(p<0.001)$, but no significant change occurred in the bond strength of the Scotchbond samples over time.

Conclusions. The microshear bond strength of resin cement to zirconia depends on the type of adhesive and the duration of water storage. The Scotchbond Universal adhesive resulted in a stronger bond in the long term.
\end{abstract}

Key words: zirconium oxide, adhesives, resin cement, All-Bond system

Słowa kluczowe: tlenek cyrkonu, systemy łączące, cement kompozytowy, system All-Bond 


\section{Introduction}

From among different dental ceramics, zirconia has become highly popular among clinicians due to its biocompatibility, favorable mechanical properties, long-term durability, and optimal esthetics. ${ }^{1}$ Zirconia can well mimic the natural appearance of the teeth. However, it is brittle, fragile and susceptible to fracture. ${ }^{2}$ Saliva, thermal changes and the acidity of the oral environment after food consumption decrease the mechanical stability of zirconia. ${ }^{3}$ Several methods have been suggested for the ceramic surface preparation, such as micromechanical retention, sandblasting with alumina particles, laser treatment, and chemical bonding. However, difficult handling of alumina particles is one limitation of this method. Thus, a strong bond is required to provide retention. For the cementation of zirconia restorations, the application of a bonding agent can significantly enhance the bond strength of resin cement to zirconia. ${ }^{4-6}$ The manufacturers claim that the universal adhesives available on the market can be used for different substrates. Two-component universal adhesives are also available. These adhesives require fewer procedural steps, which consequently saves time and decreases the technical sensitivity of the procedure. ${ }^{7}$ The new universal adhesives contain the 10-methacryloyloxydecyl dihydrogen phosphate (10-MDP) monomer and, therefore, can form a chemical bond to resin cement. ${ }^{8}$

Several studies have searched for a suitable bonding agent to be applied on zirconia, but no simple scientific method has been introduced for this purpose. This study aimed to compare the effect of 2 universal adhesives on the microshear bond strength of resin cement to zirconia after $24 \mathrm{~h}$ and 6 months of water storage.

\section{Material and methods}

Fifty-six zirconia (Prettau ${ }^{\circledR}$ Zirconia; Zirkozahn $\mathrm{GmbH}$, Gais, Italy) blocks measuring $8 \mathrm{~mm} \times 15 \mathrm{~mm} \times 2 \mathrm{~mm}$ were fabricated, sintered and polished. The surface of all samples was rinsed with alcohol and water to remove debris, and dried with air spray. The zirconia blocks were divided into 2 groups, for the Scotchbond ${ }^{\mathrm{TM}}$ Universal single-component adhesive (3M ESPE, St. Paul, USA) and the All-Bond Universal $^{\mathrm{TM}}$ 2-component adhesive (Bisco Inc., Schaumburg, USA) to be used. Each group was divided into 2 subgroups for water storage for $24 \mathrm{~h}$ and 6 months.

In the Scotchbond groups, 1 layer of Scotchbond was applied on the clean surface of the samples using a microbrush and dried with air spray to obtain a uniform layer of the adhesive on the surface. Curing was performed for $10 \mathrm{~s}$, according to the manufacturer's instructions. For the application of All-Bond, 1 drop from each bottle was poured into an amalgam mixing bowl and mixed for 10-15 s. The mixture was then applied on the surface of zirconia using a microbrush, dried with air spray and cured for $10 \mathrm{~s}$. To bond the resin cement to the zirconia blocks, the TYGON ${ }^{\circledR}$ tubes (Saint-Gobain Performance Plastics Corp., Akron, USA) with an internal diameter of $0.7 \mathrm{~mm}$ were used. They were cut to the height of $1 \mathrm{~mm}$ and fixed to glass slides using glue.

For the preparation of the PANAVIA ${ }^{\mathrm{TM}}$ F 2.0 resin cement (Kuraray Noritake Dental Inc., Kurashiki, Japan), pastes $\mathrm{A}$ and $\mathrm{B}$ were mixed according to the manufacturer's instructions, and applied to the TYGON microtubes using a fine plugger. The TYGON tubes filled with the resin cement were placed on the zirconia blocks coated with the adhesive and excess cement was removed using a dental explorer. Each cement tube was cured for $20 \mathrm{~s}$ using a light-emitting diode (LED) light-curing unit (Guilin Woodpecker Medical Instrument Co. Ltd., Guilin, China) with a light intensity of $1000 \mathrm{~mW} / \mathrm{cm}^{2}$.

After $24 \mathrm{~h}$ of water storage, the TYGON tubes were separated from the PANAVIA F 2.0 resin cement using a scalpel, whereas the resin cylinders with a diameter of $0.7 \mathrm{~mm}$ and a height of $1 \mathrm{~mm}$ remained attached to the zirconia surface. Half of the samples were subjected to the microshear bond strength test after $24 \mathrm{~h}$ of immersion in distilled water and incubation at $37^{\circ} \mathrm{C}$. The remaining half were immersed in distilled water and incubated at $37^{\circ} \mathrm{C}$ for 6 months.

The Microtensile Tester machine (Bisco Inc.) was used for the measurement of the microshear bond strength of the PANAVIA F 2.0 resin cement to the zirconia ceramic.

The zirconia blocks bonded to the resin cement were fixed to the testing machine using cyanoacrylate glue. An orthodontic wire in the form of a hook was used for the load application to the resin cylinders. These wires were fixed to the cylinders. The maximum load causing failure of the bond between the resin cylinders and zirconia was recorded for all samples.

After the measurement of microshear bond strength, the surface of all samples was inspected under a light microscope at $\times 25$ magnification (Carl Zeiss, Oberkochen, Germany) to determine the mode of failure. The mode of failure was recorded for all samples and divided into 3 groups as follows:

- adhesive failure: fracture at the zirconia-resin cement interface;

- cohesive failure: fracture within the resin cement;

- mixed failure: a combination of adhesive and cohesive failures.

Table 1 shows the chemical composition of the materials used in this study.

The Shapiro-Wilk test was used to assess normal distribution of the data. Since the data was not normally distributed in 2 of the 4 subgroups $(p<0.05)$, and the interaction effect of the type of adhesive and the storage time on bond strength was significant, the non-parametric Kruskal-Wallis test was used for comparing the bond strength of the 4 groups and the Mann-Whitney test was used for multiple comparisons (Fig. 1). Type I error was set at 0.05 . 
Table 1. Chemical composition of the materials used in the study

\begin{tabular}{|c|c|c|}
\hline Material & Composition & Manufacturer \\
\hline Prettau Zirconia & $\begin{array}{c}\mathrm{ZrO}_{2}\left(+\mathrm{HfO}_{2}\right) 95 \%, \\
\mathrm{Y}_{2} \mathrm{O}_{3} 4.95-5.26 \%, \mathrm{Al}_{2} \mathrm{O}_{3} \text { 0.15-0.35\%, } \mathrm{SiO}_{2} \max 0.02 \%, \mathrm{Na}_{2} \mathrm{O} \max 0.04 \%, \mathrm{Fe}_{2} \mathrm{O}_{3} \max 0.01 \%\end{array}$ & $\begin{array}{l}\text { Zirkonzahn GmbH, } \\
\quad \text { Gais, Italy }\end{array}$ \\
\hline Scotchbond Universal & 10-MDP, dimethacrylate resin, HEMA, ethanol, water, poly(acrylic acid) compolymer, silane, fillers, initiators & 3M ESPE, St. Paul, USA \\
\hline All-Bond Universal & 10-MDP, dimethacrylate resin, HEMA, ethanol, water, initiators & Bisco Inc., Schaumburg, USA \\
\hline PANAVIA F 2.0 & $\begin{array}{l}\text { paste A: 10-MDP, BPEDMA, aliphatic dimethacrylate; } \\
\text { paste B: composite containing Al-Ba-B-Si glass/silica }\end{array}$ & $\begin{array}{l}\text { Kuraray Noritake Dental Inc., } \\
\text { Kurashiki, Japan }\end{array}$ \\
\hline
\end{tabular}

BPEDMA - bisphenol-A polyethoxydimethacrylate; HEMA - hydroxyethylmethacrylate; 10-MDP - 10-methacryloyloxydecyl dihydrogen phosphate.

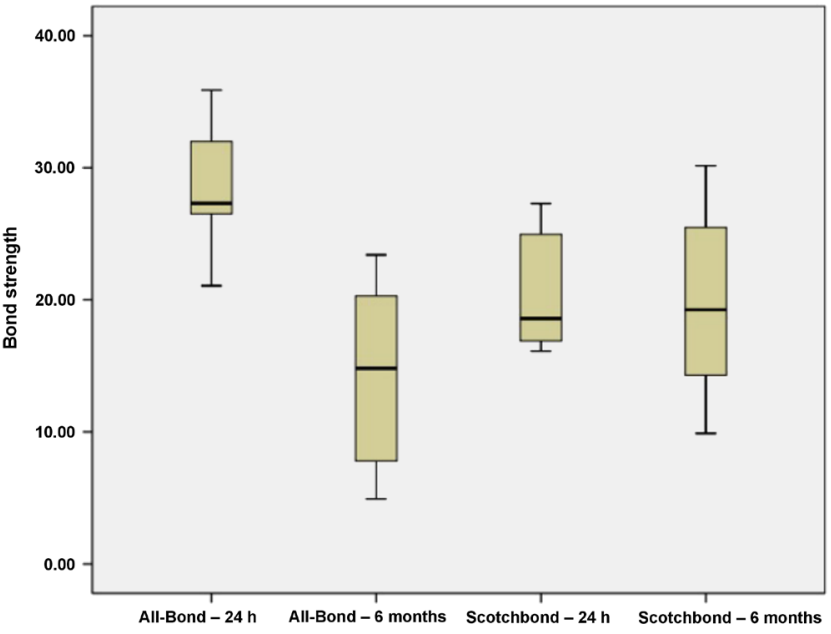

Fig. 1. Mean microshear bond strength according to the type of adhesive and the duration of storage

\section{Results}

Table 2 shows the mean bond strength in the 4 subgroups. The results of the Kruskal-Wallis test showed that the 4 subgroups were significantly different in terms of bond strength $(p<0.001)$. Pairwise comparisons using the Mann-Whitney test showed that the microshear bond strength of the All-Bond samples was significantly different after $24 \mathrm{~h}$ and 6 months of water storage, and it was significantly higher at $24 \mathrm{~h}(p<0.001)$. The bond strength of the Scotchbond samples was not significantly different at $24 \mathrm{~h}$ and 6 months $(p=0.603)$. A significant difference was noted between the All-Bond and Scotchbond samples at $24 \mathrm{~h}$ - the microshear bond strength of All-Bond was higher than that of Scotchbond $(p<0.001)$.

Table 2. Mean bond strength in the 4 subgroups $(n=14)$

\begin{tabular}{|l|c|c|c|c|}
\multicolumn{1}{|c|}{ Groups } & $\begin{array}{c}\text { Mean } \\
{[\mathrm{MPa}]}\end{array}$ & SD & Minimum & Maximum \\
\hline All-Bond - 24h & $28.52^{\mathrm{a}, \mathrm{d}}$ & 4.40 & 21.06 & 35.88 \\
All-Bond - 6 months & $14.43^{\mathrm{b}, \mathrm{e}}$ & 6.93 & 4.93 & 23.40 \\
Scotchbond - 24h & $20.42^{\mathrm{c}, \mathrm{e}}$ & 4.16 & 16.11 & 27.29 \\
\hline Scotchbond -6 months & $19.82^{\mathrm{c}, \mathrm{f}}$ & 6.76 & 9.88 & 30.16 \\
\hline
\end{tabular}

$S D$ - standard deviation; values with a different supercript letter show statistical significance $(p<0.001)$.
Figure 1 shows the comparison of All-Bond and Scotchbond. At 6 months, the Scotchbond samples proved to have higher microshear bond strength $(p=0.039)$.

A significant difference was noted between the AllBond samples stored for $24 \mathrm{~h}$ and the Scotchbond samples stored for 6 months, with the former having higher bond strength $(p=0.001)$. No significant difference was noted between the All-Bond samples stored for 6 months and the Scotchbond samples stored for $24 \mathrm{~h}(p=0.085)$. The $\chi^{2}$ test showed that the 4 groups were not significantly different in terms of mode of failure $(p=0.587)$.

\section{Discussion}

Yttrium-stabilized tetragonal zirconia is the most commonly used type of zirconia in dentistry. ${ }^{9}$ Thus, this ceramic was used in this study. PANAVIA F 2.0 contains a functional phosphate monomer (10-MDP) that forms a stronger bond to metal oxides such as zirconia oxide. Many researchers believe that PANAVIA F 2.0 is the best choice of cement for bonding to zirconia. ${ }^{10,11}$

Bonding to zirconia can be mechanical or chemical. Numerous studies have assessed the effect of sandblasting with aluminum oxide particles on the zirconia surface. It causes the tetragonal-to-monoclinic phase transformation in zirconia and eventually affects the long-term function of zirconia restorations. ${ }^{12-14}$ Phark et al. assessed the bond strength of different kinds of cement to zirconia, with and without sandblasting, and did not suggest the sandblasting of the zirconia surface to increase retention. ${ }^{15}$ Reddy et al. showed that the application of a primer provides a stronger bond between zirconia and resin cement than sandblasting. ${ }^{16}$ Thus, in this study, we did not perform sandblasting and only assessed the effect of the type of adhesive on the microshear bond strength of resin cement to zirconia.

Since single-step universal adhesives contain a combination of hydrophilic and hydrophobic resins as well as acid and water, hydrolysis occurs, and as a result, the shelf life and primary bond strength decrease. The presence of hydrophilic monomers in these adhesives interferes with polymerization. They serve as a semi-permeable membrane and allow the passage of liquids through the 
interface. This increases water sorption, swelling and disintegration. ${ }^{6,17,18}$ In 2-bottle universal adhesives such as All-Bond Universal, the components are separate, and thus the bond strength and shelf life of the adhesives increase. Hence, in the current study, we assessed the effect of these factors on microshear bond strength.

In many previous studies on the bond strength of adhesives, macro-tests have been used. Although conducting such a test and the sample preparation are easier, the rate of error and false failures increase due to the larger size of samples. ${ }^{19}$ Therefore, to obtain more accurate results, a micro-test was used for the measurement of bond strength in this study. On the other hand, since most loads applied to the teeth, especially those requiring esthetic restorations, are shear forces, the microshear bond strength test was performed in this study.

The results showed that the mean bond strength of All-Bond was higher than that of Scotchbond after $24 \mathrm{~h}$ of water storage. This difference can result from several factors. The $\mathrm{pH}$ can play a role in this respect and if the $\mathrm{pH}$ of the adhesive is acidic, the compatibility of the adhesive and the resin cement decreases. This is mainly due to the inactivation of aromatic amines by acid. These amines play an important role in the chemical curing of materials. ${ }^{20}$ Of universal adhesives, AllBond has less acidic pH (3.2) compared to Scotchbond (2.7). The 10-MDP monomer, present in All-Bond and Scotchbond, also affects bond strength. This monomer is in the composition of several materials, such as a zirconia primer. There are studies that have assessed the microshear bond strength of these materials and all have indicated the important role of this monomer in achieving high bond strength. ${ }^{21,22}$

The 10-MDP monomer has a hydrophobic methacrylate group at one end, with the ability to bond to methacrylate-based restorations and cement, and a polar phosphate group at the other end, which can bond to dental surfaces, zirconia and metal. This property alone is responsible for the optimal efficacy of this monomer used in universal adhesives. ${ }^{23,24}$ Research showed that materials with the same monomers do not necessarily possess similar properties. ${ }^{25}$ Similarly, despite the presence of the 10-MDP monomer in the composition of both adhesives in our study, different bond strength values were obtained.

The presence of the silane monomer in the composition of Scotchbond Universal is another factor causing a reduction in the bond strength of this adhesive compared to All-Bond Universal, as the silane monomer in acidic conditions (due to the presence of the MDP acidic monomer in water and $\mathrm{pH}=2.7$ ) may be unstable because of the reactions of silanol groups. Moreover, the presence of the bisphenol A-glycidyl methacrylate (BisGMA) monomer in universal adhesives along with silane and MDP in 1 bottle interferes with the bond of silane and hydroxyl groups $(-\mathrm{OH}){ }^{26}$ The new All-Bond Uni- versal adhesive is supplied in 2 bottles and is dual-cure. Thus, it has a higher polymerization rate, even in the absence of adequate light.

Our study showed that after 6 months of water storage, the All-Bond Universal adhesive showed lower bond strength than Scotchbond Universal. This was in line with the results of Davis et al., who demonstrated that bond strength decreases over time and this reduction depends on the chemical composition of the adhesives. ${ }^{27}$ One important factor affecting bond strength is the concentration of a solvent in the composition of the adhesive; higher amounts of the residual solvent dilute the monomer and limit the process of cross-linking of the resin. The solvent remaining in the polymer network forms areas of unreacted monomers that increase the susceptibility to solubility and water sorption. ${ }^{17,28}$ According to the product brochure, the approximate percentage of a solvent is 10-15\% in Scotchbond Universal and over 20\% in All-Bond Universal. This difference in the amount of a solvent affects the clinical performance of the bond and bond strength decreases over time. This is more significant for All-Bond Universal, since it has a higher percentage of a solvent.

Evidence shows that saliva and aqueous environments negatively affect the bond strength of restorations. Ito et al. and Nishitani et al. reported that water sorption occurred in universal adhesives due to the presence of hydrophilic monomers in their structure, and as a result, bond degradation appeared over time. ${ }^{29,30}$

Universal adhesives are self-etching due to the presence of hydrophilic monomers. They contain adequate concentration of water for adequate ionization of acidic monomers with no reduction in the monomer concentration for adequate bond strength. Water causes the ionization of acidic groups and results in the formation of $\mathrm{H}_{3} \mathrm{O}^{+}$ions, which cause the etching of hydroxyapatite. ${ }^{31}$ On the other hand, water enhances the elimination of the products of the etching reaction from the environment. An increase in the concentration of water decreases the concentration of acidic monomers, and consequently the strength and adequacy of the bond. An increase in the concentration of hydrophilic monomers increases water sorption over time and decreases bond strength. ${ }^{32}$

Also, there are some other explanations for the reduction of bond strength over time, such as the presence of the hydroxyethylmethacrylate (HEMA) molecule, which is small and liquid, and serves as a solvent in the structure of the bond. When the process of polymerization is almost complete, long-chain monomers in the structure of the polymer are limited. In such conditions, a low-molecular-weight molecule such as HEMA can move in the resin and react with unreacted $\mathrm{C}=\mathrm{C}$ bonds. This hydrophilic molecule causes greater water sorption in bonds with monomers such as bis-GMA. ${ }^{24}$ Scotchbond Universal showed higher stability after 6 months of water storage, which is probably due to the presence of $1-5 \%$ of the polyalkenoic acid monomer in its structure. 


\section{Conclusions}

The microshear bond strength of resin cement to zirconia depends on the type of adhesive and the duration of water storage. The bond strength of a single-component universal adhesive did not significantly change over time, but the bond strength of a 2-component universal adhesive decreased over time.

\section{ORCID iDs}

Shila Emamieh (1D https://orcid.org/0000-0003-0477-353X Mahya Elahi (D) https://orcid.org/0000-0003-2419-8106 Amir Ghasemi (D) https://orcid.org/0000-0002-2748-1778

\section{References}

1. Giordano R, Sabrosa CE. Zirconia: Material background and clinical application. Compend Contin Educ Dent. 2010;31(9):710-715.

2. McLean JW. The science and art of dental ceramics. Oper Dent 1991;16(4):149-156.

3. Kohorst $\mathrm{P}$, Borchers L, Strempel J, et al. Low-temperature degradation of different zirconia ceramics for dental applications. Acta Biomater. 2012;8(3):1213-1220.

4. Amaral R, Ozcan M, Bottino MA, Valandro LF. Microtensile bond strength of a resin cement to glass-infiltrated zirconia-reinforced ceramic: The effect of surface conditioning. Dent Mater. 2006;22(3):283-290.

5. Piascik JR, Wolter SD, Stoner BR. Development of a novel surface modification for improved bonding to zirconia. Dent Mater. 2011;27(5):e99-e105.

6. Carvalho RF, Rippe MO, Melo RM, Bottino MA, Souza ROA. Resin bond strength to zirconia: Effects of surface treatments and resin cements. Gen Dent. 2019;67(1):71-77.

7. Van Meerbeek B, De Munck J, Yoshida Y, et al. Buonocore memorial lecture. Adhesion to enamel and dentin: Current status and future challenges. Oper Dent. 2003;28(3):215-235.

8. Perdigão J, Sezinando A, Monteiro PC. Laboratory bonding ability of a multi-purpose dentin adhesive. Am J Dent. 2012;25(3):153-158.

9. Zarone F, Russo S, Sorrentino R. From porcelain-fused-to-metal to zirconia: Clinical and experimental considerations. Dent Mater. 2011;27(1):83-96.

10. Tinschert J, Natt G, Mautsch W, Augthun M, Spiekermann H. Fracture resistance of lithium disilicate-, alumina- and zirconia-based three-unit flexed partial dentures: A laboratory study. Int J Prosthodont. 2001;14(3):231-238.

11. Casucci A, Monticelli F, Goracci C, et al. Effect of surface pre-treatments on the zirconia ceramic-resin cement micro tensile bond strength. Dent Mater. 2011;27(10):1024-1030.

12. Attia A, Lehmann F, Kern M. Influence of surface conditioning and cleaning methods on resin bonding to zirconia ceramic. Dent Mater. 2011;27(2):207-213.

13. Magne $P$, Paranhos MP, Burnett LH Jr. New zirconia primer improves bond strength of resin-based cements. Dent Mater. 2010;26(4):345-352.

14. de Castro HL, Corazza PH, Paes-Júnior Tde A, Della Bona A. Influence of Y-TZP ceramic treatment and different resin cements on bond strength to dentin. Dent Mater. 2012;28(11):1191-1197.

15. Phark JH, Duarte S Jr, Blatz M, Sadan A. An in vitro evaluation of the long-term resin bond to a new densely sintered high-purity zirconium-oxide ceramic surface. J Prosthet Dent. 2009;101(1):29-38.

16. Reddy SM, Vijitha D, Deepak T, Balasubramanian R, Satish A. Evaluation of shear bond strength of zirconia bonded to dentin after various surface treatments of zirconia. J Indian Prosthodont Soc. 2014;14(1):38-41.

17. Emamieh S, Sadr A, Ghasemi A, Torabzadeh H, Akhavanzanjani V, Tagami J. Effects of solvent drying time on mass change of three adhesives. J Conserv Dent. 2013;16(5):418-422.

18. Van Meerbeek B, Yoshihara K, Yoshida Y, Mine A, De Munck J, Van Landuyt KL. State of the art of self-etch adhesives. Dent Mater. 2011;27(1):17-28.
19. Van Meerbeek B, Peumans M, Poitevin A, et al. Relationship between bond-strength tests and clinical outcomes. Dent Mater. 2010;26(2):e100-e121.

20. Schittly E, Bouter D, Le Goff S, Degrange M, Attal JP. Compatibility of five self-etching adhesive systems with two resin luting cements. J Adhes Dent. 2010;12(2):137-142.

21. Seabra B, Arantes-Oliveira S, Portugal J. Influence of multimode universal adhesives and zirconia primer application techniques on zirconia repair. J Prosthet Dent. 2014;112(2):182-187.

22. Feitosa VP, Ogliari FA, Van Meerbeek B, et al. Can the hydrophilicity of functional monomers affect chemical interaction? J Dent Res. 2014;93(2):201-206.

23. Muñoz MA, Luque-Martinez I, Malaquias $P$, et al. In vitro longevity of bonding properties of universal adhesives to dentin. Oper Dent. 2015;40(3):282-292.

24. Lim MJ, Yu MK, Lee KW. The effect of continuous application of MDP-containing primer and luting resin cement on bond strength to tribochemical silica-coated Y-TZP. Restor Dent Endod. 2018;43(2):e19.

25. Tauscher S, Angermann J, Catel Y, Moszner N. Evaluation of alternative monomers to HEMA for dental applications. Dent Mater. 2017;33(7):857-865.

26. Lung $C Y$, Matinlinna JP. Aspects of silane coupling agents and surface conditioning in dentistry: An overview. Dent Mater. 2012;28(5):467-477.

27. Davis EL, Joynt RB, Yu X, Wieczkowski G Jr. Dentin bonding system shelf life and bond strength. Am J Dent. 1993;6(5):229-231.

28. Cadenaro M, Breschi L, Rueggeberg FA, et al. Effects of residual ethanol on the rate and degree of conversion of five experimental resins. Dent Mater. 2009;25(5):621-628.

29. Ito $S$, Hashimoto $M$, Wadgaonkar B, et al. Effects of resin hydrophilicity on water sorption and changes in modulus of elasticity. Biomaterials. 2005;26(33):6449-6459.

30. Nishitani $Y$, Yoshiyama M, Donnelly AM, et al. Effects of resin hydrophilicity on dentin bond strength. J Dent Res. 2006;85(11):1016-1021.

31. Hosaka K, Nakajima M, Takahashi M, et al. Relationship between mechanical properties of one-step self-etch adhesives and water sorption. Dent Mater. 2010;26(4):360-367.

32. Malacarne J, Carvalho RM, de Goes MF, et al. Water sorption/solubility of dental adhesive resins. Dent Mater. 2006;22(10):973-980. 